\title{
Canada's own "Dr. Safety"
}

\author{
A Lifetime in Safety \\ Ed Napke \\ Uppsala Monitoring Centre; 2011.
}

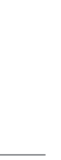

$\mathrm{T}$ his compilation of previously published articles by Dr. Ed Napke, founder of the Canadian Adverse Drug Reaction (ADR) Reporting Program, is largely a chronicle of how the program, now called the Canada Vigilance Program, was developed by Health Canada.

Although the articles are dated, learning how the program was begun and how it evolved gives the reader a perspective on the significance of reporting ADRs for the purpose of contributing to the safer use of medicines in Canada. The articles cover a wide range of ADR-related topics, including why reporting is important, the roles of different health care practitioners and how reports used to be monitored and prioritized to generate safety alerts. Health care professionals as well as members of the public would find it an interesting read.

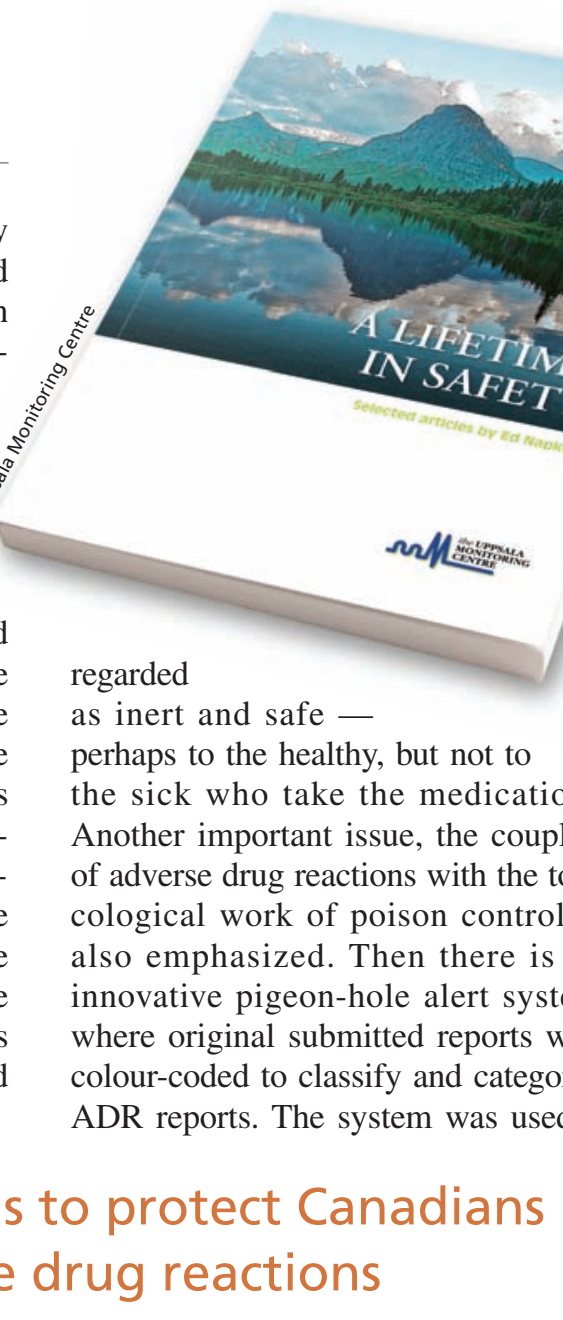

The author's initial ideas, and the philosophy expressed in the beginning of the book are worthy of note, specifically his conviction about the potential harmful effects of excipients (pharmacologically inactive substances used as a carrier for the active ingredients of a medication). These were always flag emerging problems; a creative and effective approach in the 1960s, before the use of computers. Napke also identified the need for future data collection and analysis in several important population groups. These include those with mental health conditions, women (especially pregnant women), older patients and Aboriginal people, to name a few. I believe that following his cue, improvement has been made in addressing adverse drug reactions in some of these groups, particularly regarding medications used by those with mental health conditions.

Worth mentioning is the development in ADR reporting programs to focus on the root cause of reactions. Many reported reactions, although triggered by the drug in question, could be the effect of an "error" resulting from a practitioner's drug knowledge deficit or of a process error that results in the drug dose being either above or below the therapeutic range. ADR reporting and monitoring centres should therefore learn to separate the real, nonpreventable reactions, those due to idiosyncrasies of a drug molecule, from preventable incidents that are related to human error.

This book provides an opportunity to honour Napke by learning about his passion and his tremendously keen interest in helping to protect Canadians from adverse drug reactions. Napke's achievements, as reflected in this book, have surely made a huge impact in the evolution of similar programs in other countries.

\section{David U BScPhm MScPhm \\ President and CEO \\ Institute for Safe Medication Practices \\ Canada \\ Toronto, Ont.}

CMAJ 2011. DOI:10.1503/cmaj.111410 